\title{
EFFECTIVENESS OF TOOTHPASTE CONTAINING PROPOLIS, TEA TREE OIL, AND SODIUM MONOFLUOROPHOSPHATE AGAINST PLAQUE AND GINGIVITIS
}

\author{
NELLY SURIAMAH ${ }^{1}$, ROBERT LESSANG ${ }^{2 *}$, YULIANTI KEMAL $^{2}$ \\ ${ }^{1}$ Undergraduate Program, Faculty of Dentistry, Universitas Indonesia, Jakarta 10430, Indonesia. ${ }^{2}$ Department of Periodontics, Faculty of \\ Dentistry, Universitas Indonesia, Jakarta 10430, Indonesia. Email: robertlessang@gmail.com
}

Received 25 September 2018, Revised and Accepted 22 February 2019

\section{ABSTRACT}

Objective: Natural ingredients such as propolis and tea tree oil are known to possess antibacterial and anti-inflammatory effects that are effective against periodontal diseases. This study aimed to determine the effectiveness of toothpaste containing propolis, tea tree oil, and sodium monofluorophosphate against dental plaque and gingivitis.

Methods: A randomized clinical trial was conducted for 7 days with 20 subjects in test (using the experimental toothpaste) and control (using toothpaste without any natural ingredients) groups each. Measurements of plaque index (PI) and papillary bleeding index (PBI) scores were performed on days 0 and 7 .

Results: Significant decreases $(\mathrm{p}<0.05)$ in PI $(0.53-0.27)$ and PBI $(0.55-0.11)$ scores were noted in the test group but not in the control group.

Conclusions: Brushing teeth with toothpaste containing propolis, tea tree oil, and sodium monofluorophosphate might be effective in reducing the accumulation of dental plaque and the severity of gingival bleeding.

Keywords: Gingivitis, Plaque index, Propolis, Tea tree oil.

(c) 2019 The Authors. Published by Innovare Academic Sciences Pvt Ltd. This is an open access article under the CC BY license (http://creativecommons. org/licenses/by/4. 0/) DOI: http://dx.doi.org/10.22159/ijap.2019.v11s1.AR172

\section{INTRODUCTION}

Periodontal disease, an inflammatory disease, is caused by bacteria in the oral cavity [1] Gingivitis is the most common form of periodontal disease, affecting $>90 \%$ of the Indonesia population [2]. It is a non-specific inflammatory response of the gingiva to dental plaque without loss of periodontal attachment [3]. Dental plaque, the main causative factor of gingivitis, is a yellow-gray structure that is firmly attached to the tooth surface and contains pathogenic microorganisms [4].

Propolis, a resin adhesive material, is collected by worker bees from buds, plant skin, and other parts of a plant. The resins obtained from various plants are mixed with the saliva and enzymes of the bees [5]. Propolis contains 150->300 components [6], with flavonoids being the most important and abundant chemical compounds. In addition to the 12 different flavonoids in propolis (apigenin, quercetin, pinocembrin, acacetin, chrysin, rutin, catechin, naringenin, galangin, luteolin, kaempferol, and myricetin), the presence of two phenolic acids (cinnamic acid and caffeic acid) and one stilbene derivative (resveratrol) has been determined in propolis extracts [7].

Propolis possesses antibacterial, antiviral, anti-inflammatory, antioxidant, and anticariogenic properties, and it is used by humans to boost the immune system [8]. Most of its biological activities occur due to the presence of flavonoids [7]. Propolis exhibits effective bactericidal activity against Gram-positive bacteria and limited action to Gram-negative bacteria [9]. Moreover, the presence of flavonoids and phenolic acids in propolis has an active effect against bacteria, fungi, and viruses.

In dentistry, propolis is used for the treatment of aphthous ulcer, candidiasis, acute necrotizing ulcerative gingivitis, gingivitis, periodontitis, and pulpitis [8]. Numerous study compared the effectiveness of propolis with antibiotics such as doxycycline, tetracycline, metronidazole, ofloxacin, and amoxicillin against Porphyromonas gingivalis, Prevotella intermedia, and Fusobacterium nucleatum in vitro and showed that these periodontal pathogens were more susceptible to propolis than antibiotics [10].

Tea tree oil (TTO), a native Australian plant, is a volatile essential oil derived from Melaleuca alternifolia. Its antibacterial component is primarily derived from terpinen-4-ol, which is a major component of this essential oil [11]. TTO is naturally bactericidal, although it can also demonstrate bacteriostatic activities at lowSer concentrations. Most bacteria are susceptible to TTO at concentrations of $\leq 1.0 \%$, including P. gingivalis and Prevotella spp. Experiments using a $0.2 \%$ TTO-containing mouthwash reduced the numbers of Streptococcus mutans and other bacteria in the mouth. In another study, the use of a TTO gel $(2.5 \%)$ reduced the gingival index and papilla bleeding score in medically fit non-smokers with severe chronic gingivitis [11]. Furthermore, TTO is known to have anti-inflammatory effects due to the presence of terpinen-4-ol [11,12].

Toothbrushing without using toothpaste removes only approximately $50 \%$ of dental plaque; mechanical cleaning and the use of antibacterial agents are also required to remove any residual plaque [13]. Toothpastes contain active and non-active ingredients; active ingredients offer therapeutic benefits, whereas inactive ingredients have no therapeutic functions but contribute to the physicochemical properties of toothpaste such as consistency, taste, $\mathrm{pH}$, texture, ability to penetrate, and appearance [14]. Sodium monofluorophosphate, an odorless white to gray powder, is used as a source of fluoride. It is commonly added as an anticaries agent in toothpastes and mouthwashes [15].

The present study was conducted to determine the effectiveness of toothpaste containing propolis, TTO, and sodium monofluorophosphate against plaque and gingivitis. 
Int J App Pharm, Vol 11, Special Issue 1, 2019

\section{METHODS}

\section{Subjects}

In total, 40 students from the Fakultas Kedokteran Gigi, Universitas Indonesia, were selected and divided into test and control groups $(n=20$ each). The inclusion criteria in this study were as follows: (1) Young adults (aged 17-25 years) with good general health; (2) those suffering from gingivitis (evidence of gingival bleeding); and (3) those who approved of the research process and provided the required informed consent. The exclusion criteria included the following: (1) Presence of systemic disease; (2) occurrence of periodontitis (periodontal pocket formation); (3) use of a fixed dental prosthesis or orthodontic appliance; (4) pregnancy; and (5) use of toothpaste with natural ingredients during the study.

\section{Treatment}

The subjects included in the study were informed about the treatment procedure and were required to sign the consent forms and supplementary data sheets. On day 0 , plaque index (PI) of Löe and Sillness and papillary bleeding index (PBI) of Saxer and Mühlemann were noted following the initial examination of the subjects. Next, the test subjects were provided with the test toothpaste, and the remaining control subjects were asked to continue using the toothpaste they normally used (without natural ingredients). The subjects were instructed to brush their teeth with the respective toothpastes twice a day, morning and night for 7 consecutive days, without using any additional mouth cleansers such as mouthwash, toothpicks, and dental floss; in addition, they were asked to refrain from fasting and undergoing scaling treatment during the study period. On day 7, a final examination of PI and PBI was conducted in the same manner and region as on day 0 , and the results were noted.

\section{Statistical analysis}

SPSS computer program was used for data analysis. The Shapiro-Wilk test $(\mathrm{n}<50)$ was used to test the distribution of samples followed by a parametric t-test. In each group, significant differences before and after the treatment were determined using the paired t-test; unpaired t-test was used to determine the presence of significant differences between the two groups. The significance level was set at $5 \%(\mathrm{p}=0.05)$ and the confidence level at $95 \%(\alpha=0.05)$

\section{RESULTS}

Table 1 illustrates the frequency of distribution following treatment. All subjects in the test group experienced a decrease in PI and PBI scores after using the test toothpaste for 7 days, with three of them $(15 \%)$ experiencing healing gingival inflammation $(\mathrm{PBI}=0)$. Meanwhile, in the control group, an increase and decrease in PI and PBI scored, respectively, were observed after the examination on day 7 .

The average initial and final PI and PBI values in the test and control groups are presented in Table 2. The mean decrease in PI values in the test group was significantly greater $(p<0.05)$ at 0.26 when compared with that in the control group (0.01). Similarly, the mean decrease in the PBI values in the test group $(0.44)$ was significantly greater $(\mathrm{p}<0.05)$ than that in the control group $(0.05)$.

Based on the results of the paired t-test, a significant difference $(p<0.05)$ in terms of mean PI and PBI scores was noted in the test group after final measurement on day 7, whereas no such significant differences in scores were observed in the control group. The unpaired t-test revealed a significant difference $(\mathrm{p}<0.05)$ in terms of the mean values between the test and control groups.

\section{DISCUSSION}

In the present study, the effectiveness of toothpaste containing propolis, TTO, and sodium monofluorophosphate against plaque and gingivitis was evaluated in 20 test and 20 control subjects. Based on the results, $15 \%$ of the test subjects did not experience bleeding during probing $(\mathrm{PBI}=0)$ on day 7 of the examination, indicating that the toothpaste was
Table 1: Distribution frequency after the treatment in the test and control groups

\begin{tabular}{lll}
\hline Variable test group & n amount (\%) & Cumulative (\%) \\
\hline $\begin{array}{l}\text { PI index } \\
\text { PI decrease }\end{array}$ & $20(100)$ & 100 \\
$\begin{array}{l}\text { PBI index } \\
\text { PBI decrease }\end{array}$ & $20(100)$ & 100 \\
Control group & & \\
$\quad$ PI index & $9(45)$ & 45 \\
$\quad$ PI decrease & $1(5)$ & 50 \\
$\quad$ PI consistent & $10(50)$ & 100 \\
$\quad$ PI increase & $12(60)$ & 60 \\
PBI index & $1(5)$ & 65 \\
PBI decrease & $7(35)$ & \\
PBI consistent & PBI increase &
\end{tabular}

PI: Plaque index, PBI: Papillary bleeding index

Table 2: Mean PI and PBI values in the test and control groups on days 0 and 7

\begin{tabular}{llllllll}
\hline Groups & \multicolumn{2}{l}{ PI Mean } & \multirow{2}{*}{ Difference } & \multicolumn{2}{l}{ PBI Mean } & \multirow{2}{*}{ Difference } \\
\cline { 2 - 3 } \cline { 5 - 6 } & Day 0 & Day 7 & & & Day 0 & Day 7 & \\
\hline Control & 0.43 & 0.42 & 0.01 & 0.34 & 0.29 & 0.05 \\
Test & 0.53 & 0.27 & 0.26 & 0.55 & 0.11 & 0.44 \\
\hline
\end{tabular}

PI: Plaque index, PBI: Papillary bleeding index

effective in healing gingivitis. The use of toothpastes containing natural ingredients such as propolis and TTO appeared to be more effective against plaque accumulation and gingival bleeding than those without any natural ingredients.

The components of propolis, particularly polyphenolics in the form of apigenin and tt-farnesol, reportedly possess antibacterial activity $[9,16]$. Koo et al. showed that apigenin may act as an inhibitor of the enzyme glucosyltransferase, which converts sucrose into an extracellular polysaccharide that can increase the attachment and accumulation of cariogenic bacteria on the tooth surface [16]. The tt-fernesol component of propolis may affect the integrity of bacterial membrane by destroying the inner membrane and also inhibit protein synthesis and the mobility of bacteria $[9,16]$. In addition, TTO exerts antibacterial effects by destroying the integrity and function of the membrane, resulting in loss of intracellular material. Hence, the cell is unable to maintain homeostatic balance, inhibiting cell respiration [17].

In line with the study by Peck et al., where a toothpaste containing TTO along with fluoride more significantly inhibited bacterial growth than that containing TTO without fluoride, the current study also used a toothpaste containing natural ingredients in combination with sodium monofluorophosphate [13]

Propolis has been shown to have anti-inflammatory effects in vivo and in vitro in acute and chronic cases [18]. These effects are produced by polyphenolics (flavonoids, phenolic acids, and esters), terpenoids, steroids, and amino acids. The anti-inflammatory effects are exerted by the inhibition of cyclooxygenase and prostaglandin biosynthesis, reduction of cytokine concentrations, and immunosuppression [18]. Amaral et al. demonstrated that propolis applied to periodontal pockets can reduce the severity of gingivitis and pus formation by up to $95 \%$ [19]. In addition, the anti-inflammatory effect is demonstrated by the TTO component 4-ol terpinen; this component can reduce the production of tumor necrosis factor- $\alpha$, interleukin (IL)- $1 \beta$, IL-8, IL-10, and prostaglandin E2, which play important roles in the inflammatory process through monocyte activation $[11,12]$.

A previous study suggested that the use of herbal toothpastes can more effectively decrease the accumulation of plaque on the tooth surface and 
proximal areas, decrease gingival inflammation, and reduce bleeding in the gingival sulcus than the use of conventional toothpastes [20]. In another study, a toothpaste containing propolis was found to inhibit dental plaque formation and decrease the PI score [7]

In the current study, the variations in PI and PBI values in the control group may be due to improved brushing habits by some subjects due to the awareness that they were being observed. Moreover, different levels of oral health knowledge and variations in the contents of the toothpastes used by the subjects may have affected the final result.

\section{CONCLUSIONS}

The use of toothpaste containing propolis, TTO, and sodium monofluorophosphate was found to decrease plaque accumulation and severity of gingival bleeding, which was confirmed by the decrease in PI and PBI scores among all test subjects. However, further, research is warranted to determine the optimal concentration of propolis and TTO in the toothpaste and its effect on certain oral bacteria in vivo and in vitro.

\section{CONFLICTS OF INTEREST}

The authors report no conflicts of interest.

\section{REFERENCES}

1. Van Dyke TE. The management of inflammation in periodontal disease. J Periodontol 2008;79:1601-8.

2. Somu CA, Ravindra S, Ajith S, Ahamed MG. Efficacy of a herbal extract gel in the treatment of gingivitis: A clinical study. J Ayurveda Integr Med 2012;3:85-90.

3. Beck JD, dan Samuel JA. Epidemiology of gingival and periodontal disease. In: Carranza FA, Newman MG, Takei HH, editors. Carranza's Clinical Periodontology. $10^{\text {th }}$ ed. Philadelphia, PA: WB. Saunders Co.; 2006. p. 110-31.

4. Hinrichs JE. The role of dental calculus and other predisposing factors. In: Newman MG, Takei HH, ediotrs. Carranza's Clinical Periodontology. $10^{\text {th }}$ ed. Philadelphia, PA: WB. Saunders Co.; 2006. p. $170-87$.

5. Anggraini AD. Potential Effect of Propolis Potensi Propolis Honey Bee
Trigona Spp as an Antibacterial Material, Dissertation; 2006.

6. Halim E. Propolis Serta Efek Imunomodulator Terhadap Sel T CD8+ pada Pasien Kanker Payudara. Thesis; 2011. p. 9-12.

7. Aisyiyah N. Effect of Toothpaste with Propolis Content towards Developing of Plaque. [Scientific Article]. Semarang: Faculty of Medicine, Universitas Diponegoro; 2012. p. 1-14.

8. Ahuja V, Ahuja A. Apitherapy a sweet approach to dental disease. Part II: Propolis. J Acad Adv Dent Res 2011;2:1-6.

9. Bogdanov S. Propolis: Composition, health, medicine: A review. Bee Prod Sci 2012;1:1-40.

10. Gebara E, Lima L, Mayer M. Propolis antimicrobial activity against periodontopathic bacteria. Braz J Microbiol 2002;33:365-9.

11. Carson CF, Hammer KA, Riley TV. Melaleuca alternifolia (Tea tree) oil: A review of antimicrobial and other medicinal properties. Clin Microbiol Rev 2006;19:50-62.

12. Hart PH, Brand C, Carson CF, Riley TV, Prager RH, Finlay-Jones JJ, et al. Terpinen-4-ol, the main component of the essential oil of Melaleuca alternifolia (tea tree oil), suppresses inflammatory mediator production by activated human monocytes. Inflamm Res 2000;49:619-26.

13. Peck MT, Africa CW, Stephen LX, Marnewick J, Majeed A. An in vitro analysis of the antimicrobial efficacy of herbal toothpastes on selected primary plaque colonizers. Int J Clin Dent Sci 2011;2:28-32.

14. Collins FM. Ingredients Benefits Recommendations: Reflections on Dentifrice Ingredients, Benefits and Recommendations. Vol. 7. A Peer Review Publication; 2006. p. 1-8.

15. Storehagen S, Ose N. Dentifrices and Mouthwashes Ingredients and their Use. Oslo: University of Oslo; 2003:1-44.

16. Koo H, Hayacibara MF, Schobel BD, Cury JA, Rosalen PL, Park YK, et al. Inhibition of Streptococcus mutans biofilm accumulation and polysaccharide production by apigenin and tt-farnesol. J Antimicrob Chemother 2003;52:782-9.

17. Soukoulis S, Hirsch R. The effects of a tea tree oil-containing gel on plaque and chronic gingivitis. Aust Dent J 2004;49:78-83.

18. Araujo MA, Libério SA, Guerra RN, Riberio MN, Nascimento FR. Mechanisms of action underlying the antiinflammatory and immunomodulatory effects of propolis: A brief review. Rev Bras Farmacogn 2012;22:208-19.

19. Amaral RC, Gomes RF, Rocha WM, Lemos S, Abreu R, Santos VR. Periodontitis treatment with Brazilian green propolis gel. Pharmacology 2006;3:336-41

20. Al-Kholani AI. Comparison between the efficacy of herbal and conventional dentifrices on established gingivitis. Dent Res J (Isfahan) 2011;8:57-63. 